\title{
Aprendizagem colaborativa docente: fatores facilitadores e inibidores no contexto escolar
}

\section{Teacher collaborative learning: facilitating and inhibiting factors in the school context}

\author{
Ana Maria Costa e Silva*, Rosalinda Herdeiro**, Sílvia Cunha* \\ * Instituto de Educação, Universidade do Minho, ** Agrupamento de Escolas de Pedome
}

\begin{abstract}
Resumo
O desempenho profissional docente tem grande relevância no que concerne a questões relativas à melhoria do sistema educativo e do sucesso escolar. Neste sentido, é importante a aprendizagem contínua dos professores e a criação de oportunidades de aprendizagem profissional em contexto de trabalho sob abordagem colaborativa, potenciando relações, conhecimentos e competências. No estudo realizado, através de uma metodologia qualitativa, foram aplicadas nove entrevistas a professores e elementos da direção de um agrupamento de escolas do norte de Portugal, que posteriormente foram sujeitas a análise de conteúdo. Os resultados revelam que existem iniciativas facilitadoras da aprendizagem colaborativa e fatores que dificultam o seu desenvolvimento no contexto escolar.

Palavras-chave: aprendizagem colaborativa, desempenho docente, ensino de qualidade.
\end{abstract}

\begin{abstract}
Teacher professional performance is very important, as it concerns questions related to the improvement of the educational system and school success. In this sense, it is important to initiate the continuing learning of teachers and the creation of opportunities for professional learning in their working context by means of collaborative learning and the strengthening of relationships, knowledge and competencies. In the study carried out using a qualitative methodology nine interviews were conducted with teachers and members of the directorate of a group of schools in the north of Portugal, which later on were subjected to content analysis. The results of this analysis revealed that there were initiatives that facilitated collaborative learning and also factors that made it difficult for its development in the school context.
\end{abstract}

Keywords: collaborative learning, teacher performance, quality education.

\section{Introdução}

Nas últimas décadas, temos assistido ao desenvolvimento de políticas educativas que se inscrevem numa agenda globalmente estruturada, no sentido de que as decisões nacionais são circunscritas pelas dinâmicas e relações político-económicas globais.

Assim, no que se refere à educação há uma evidente influência da Europa, nomeadamente a partir dos últimos anos da década de noventa do século passado, que podemos considerar uma nova fase do processo de europeização das políticas educativas e de formação, traduzida na intensificação da construção de entendimentos, orientações e normas de ação comuns às políticas educativas nacionais dos países-membros.

Neste sentido, a partir do momento em que na generalidade dos países mais desenvolvidos se pode afirmar como atingido o grande objetivo da universalidade do princípio da escolaridade obrigatória, surge como propósito estruturante da evolução dos respetivos sistemas educativos a necessidade de um ensino de qualidade.

Para Darling-Hammond (2010), a qualidade do ensino está associada a um ensino sólido que permite a aprendizagem de uma grande diversidade de alunos e que vai ao encontro das exigências da disciplina, dos objetivos de aprendizagem e das necessidades dos alunos num determinado contexto. Neste processo, o papel do professor centra-se na criação de contextos e ambientes adequados para que o aluno possa desenvolver suas habilidades sociais e cognitivas de modo criativo, na interação com os outros.

A desejada qualidade de ensino exige que os professores sejam bem formados, altamente motivados, com conhecimentos e capacitados, não apenas no início da sua carreira como também ao longo de todo o percurso profissional (Day \& Sachs, 2004).

Deste modo, o investimento na qualidade das escolas e dos professores é considerado a base e o instigador de desenvolvimento, criando, desta forma, novas responsabilidades sobre os sistemas educativos e, simultaneamente, atribui-se maior importância à aprendizagem colaborativa docente. Ou seja, pretende-se sublinhar a importância de os professores terem um lugar predominante na formação dos seus pares, partindo do pressuposto de que a reflexão sobre o seu próprio trabalho em conjunto é fundamental.

Numa conferência, Snoek (2007) afirma que ao transformar-se o desenvolvimento profissional dos professores numa responsabilidade partilhada no seio da escola, gera-se uma maior ênfase na aprendizagem colaborativa dos professores e na criação de uma cultura de questionamento dentro das escolas. 
Segundo Ross e Bruce (2007), esta cultura de questionamento concebe o desenvolvimento profissional como uma tarefa coletiva, baseada em relações de aprendizagem mútua e, concomitantemente, como um estímulo para melhorar as crenças dos professores acerca da sua capacidade de ocasionar a aprendizagem do aluno.

Assim, é importante que no processo de aprendizagem colaborativa docente haja sentido de responsabilidade e que os docentes se apoiem mutuamente na consecução de um objetivo comum do grupo. Desta forma, interessa que os docentes decidam em conjunto modos e formas de trabalho interativo, sobre o currículo formal e não formal, regulando-o e modificando-o, de acordo com processos e resultados obtidos (Ponte, 2004).

$\mathrm{Na}$ opinião de Costa (2008), a aprendizagem colaborativa docente pressupõe a operacionalização de estratégias e atividades organizadas coletivamente, em que a tarefa de um complementa o trabalho de outros. Esta interdependência exige interação permanente, respeito das ideias, diálogo, seriedade e compromisso. Neste sentido, podemos considerar que a aprendizagem colaborativa docente é consequência da assunção de princípios de interajuda e empatia com os outros.

Tavares (1996) afirma que é através deste tipo de relações de ajuda que se consegue entrar verdadeiramente dentro das pessoas, senti-las, compreende-las e respeitá-las, procurando ajudar no sentido de criar liberdade e espaço para evitar os obstáculos e, ao mesmo tempo, sentir segurança e informação suficientes para resolver os problemas que vão surgindo.

O trabalho docente colaborativo, na opinião de Davezies (1993), implica uma atividade de construção de regras, supostamente conferida na existência de espaços e momentos formais e/ou informais de debate que permitam a troca de experiências e saberes profissionais. Estes espaços, principalmente os informais, são dotados como os mais suscetíveis de construir confiança e conhecimento entre os professores, apesar de serem considerados como não produtivos (Idem).

A motivação do professor para a aprendizagem assume um lugar de destaque na promoção de um ensino de qualidade, tornando-se, assim, prioritário criar condições para que se sinta bem e realizado no seu trabalho.

Por seu turno, as políticas educativas e curriculares do momento também podem interferir, principalmente quando as mesmas acarretam maior exigência de novas tarefas que, associadas ao excesso de burocracia, deixam pouco tempo ao professor para pensar no ensino.

A este respeito, Apple e Jungck (1992) afirmam que a intensificação de tarefas leva os professores a 'cortar caminho', de modo que seja realizado apenas o que é solicitado no imediato sem previamente haver lugar para a reflexão e aprendizagem em conjunto.

Neste contexto, conhecer os fatores que facilitam e inibem a aprendizagem colaborativa docente na escola, poderá ser importante no processo de tomada de decisões dos órgãos de gestão, orientando-os na construção de condições de trabalho adequadas à aprendizagem.

\section{Método}

A investigação realizada inscreve-se num projeto sobre "Aprendizagem profissional colaborativa de professores", levado a cabo em Portugal e no Chile. Os principais objetivos deste estudo são: i) Compreender o modo como os professores descrevem as oportunidades formais e informais de partilha na sua escola e que efeitos têm ao nível do seu conhecimento prático; ii) conhecer os elementos facilitadores e inibidores da aprendizagem profissional colaborativa no local de trabalho; iii) analisar o modo como professores de diferentes disciplinas, anos de experiência e tipo de estabelecimento perspetivam a sua aprendizagem profissional no local de trabalho.

Trata-se de uma investigação de natureza qualiquantitativa (Bryman, 1988), recorrendo ao método de estudos de caso (Yin, 1994; Stake, 1995) em escolas/agrupamentos públicos e privados.

Neste texto apresentam-se os resultados parciais de um dos estudos de caso realizado com professores num Agrupamento de Escolas TEIP situado na zona norte de Portugal; ou seja, incide-se essencialmente na análise dos resultados relativos aos elementos facilitadores e inibidores da aprendizagem profissional colaborativa no local de trabalho, identificados pelos professores entrevistados.

\section{Participantes}

O Agrupamento de Escolas em que foi efetuado o estudo é uma instituição pública, criada em 2005. Tem um total de 130 professores e de 1456 alunos da educação pré-escolar, $1^{\circ}, 2^{\circ}$ e $3^{\circ}$ Ciclos da Ensino Básico.

Os resultados que apresentamos resultam das entrevistas realizadas ao Diretor do Agrupamento e a 8 professores, com diferentes cargos, distintos anos de experiência e oriundos de diferentes grupos disciplinares. $\mathrm{Na}$ tabela seguinte encontram-se sistematizadas as principais características dos professores participantes.

Tabela 1.

Características sociodemográficas dos participantes

\begin{tabular}{|c|c|c|c|c|c|}
\hline Código & Cargo & Idade & Sexo & $\begin{array}{c}\text { Tempo } \\
\text { de } \\
\text { serviço }\end{array}$ & $\begin{array}{c}\text { Anos de } \\
\text { trab. no } \\
\text { Agrup. }\end{array}$ \\
\hline PA & Diretor & 57 & M & 37 & 10 \\
\hline PB & Coord. $1^{\circ}$ ceb & 52 & $\mathrm{~F}$ & 30 & 8 \\
\hline $\mathrm{PC}$ & $\begin{array}{l}\text { Coord. } \\
\text { Línguas }\end{array}$ & 47 & $\mathrm{~F}$ & 20 & 8 \\
\hline PD & $\begin{array}{l}\text { Coord. } \\
\text { Ciências }\end{array}$ & 52 & $\mathrm{~F}$ & 25 & 12 \\
\hline PE & Coord. CSH & 53 & $\mathrm{~F}$ & 28 & 15 \\
\hline $\mathrm{PF}$ & $\begin{array}{c}\text { Coord. } \\
\text { Expressões }\end{array}$ & 46 & $\mathrm{~F}$ & 22 & 10 \\
\hline PG & $\begin{array}{l}\text { Coord. Pré- } \\
\text { escolar }\end{array}$ & 61 & $\mathrm{~F}$ & 37 & 10 \\
\hline PH & Prof. $1^{\circ}$ ciclo & 42 & M & 18 & 2 \\
\hline PI & Prof. $2^{\circ}$ ciclo & 39 & M & 18 & 15 \\
\hline
\end{tabular}


$\mathrm{Na}$ tabela anterior percebe-se que no grupo de professores entrevistados prevalecem as mulheres, têm idades inscritas no intervalo dos 39 aos 61 anos, são coordenadoras de diferentes grupos disciplinares e de diferentes níveis de ensino. Todas os entrevistados têm mais de 18 anos de trabalho docente, e apenas um dos professores entrevistado tem 2 anos de trabalho no Agrupamento. Todos os outros têm mais de 8 anos, ou seja quase todos com uma década ou mais de continuidade no mesmo Agrupamento/Escola.

\section{Instrumentos}

Para a recolha de informação recorreu-se a 3 instrumentos: a) ficha de caracterização do Agrupamento; b) inquérito por questionário - escala tipo likert com 13 itens - administrado a todos os professores e educadores da escola; c) um protocolo de entrevista semi-estruturada com um guião de perguntas, previamente disponibilizado ao Diretor do Agrupamento e aos professores que se disponibilizaram a participar na investigação.

\section{Procedimentos}

A recolha dos dados foi realizada entre setembro e dezembro de 2016. Após a obtenção da autorização do Ministério da Educação para a realização do estudo, bem como do consentimento informado por parte do Agrupamento, foi preenchida a ficha de caracterização do mesmo com os dados recolhidos junto da Direção. Em seguida, foram ministrados os questionários aos 130 professores, tendo respondido ao mesmo 95 (73\% do total de docentes). Em novembro e dezembro foram efetuadas as 9 entrevistas. Todas as entrevistas foram precedidas do consentimento informado e conhecimento prévio do guião pelos entrevistados. Foram todas gravadas em registo áudio, com a autorização prévia para o mesmo. As entrevistas tiveram uma duração que variou entre 30 minutos e $1 \mathrm{~h} 30$. Posteriormente, foram integralmente transcritas e analisado o seu conteúdo a partir de categorias prévias previstas para a análise de todas as entrevistas da investigação.

\section{Resultados}

Como temos vindo a referir ao longo do texto, a aprendizagem colaborativa docente implica uma situação de aprendizagem na qual dois ou mais professores, partilham as suas experiências de trabalho, identificam dificuldades que procuram resolver conjuntamente, questionando, refletindo e consolidando conhecimentos. Esta aprendizagem pressupõe contextos optimizadores que permitam a reflexão em coletivo, a disponibilidade e motivação dos docentes para o trabalho em equipa e a dinamização de formação contínua centrada na escola.

Nesta perspetiva, criar dispositivos e contextos que levem o professor a uma atitude consequente de investimento profissional é uma necessidade que as escolas devem programar e direcionar nesse sentido. Não se pretende tanto proporcionar saberes formalizados, mas antes criar condições e oportunidades de aprendizagem colaborativa que permitam a troca de experiências pedagógicas, com o propósito de enriquecer o trabalho docente.
Promover a aprendizagem colaborativa no local de trabalho é reforçado por Smylie (1995), ao salientar as oportunidades dos professores para trabalhar e aprender com os pares numa base contínua, acreditando que a aprendizagem pode ser melhorada através da partilha com os outros, particularmente com aqueles que possuem conhecimentos e experiências diferentes.

Por sua vez, o processo de aprendizagem colaborativa docente exige tempo, disponibilidade e uma relação de confiança entre pares, para que a capacidade de resposta aos problemas não seja comprometida.

Neste sentido, o conhecimento dos resultados inferidos desta investigação, torna-se pertinente para a elaboração de um plano de desenvolvimento profissional nas escolas, onde a aprendizagem colaborativa assumirá um lugar privilegiado.

Assim, a análise das entrevistas dos professores que participaram nesta investigação permite-nos conhecer os fatores que potenciam a aprendizagem colaborativa - as relações entre colegas; as reuniões informais; trabalhar em projeto - e os que a dificultam ou inibem - a resistência docente; a falta de tempo; o excesso de burocracia; as novas exigências e o desgaste profissional.

Nas tabelas que se seguem são legíveis os resultados mais manifestos apurados nesta investigação, apresentados intencionalmente sob ordem de "mais mencionados" para "menos mencionados" pelos respetivos entrevistados. Aleatoriamente, alguns fatores foram complementados com citações dos participantes.

Tabela 2.

Fatores facilitadores da aprendizagem colaborativa docente

\begin{tabular}{|c|c|}
\hline \multicolumn{2}{|r|}{ Fatores Facilitadores } \\
\hline $\begin{array}{l}+ \\
1\end{array}$ & $\begin{array}{l}\text { Relacionamento entre colegas: "à-vontade”, } \\
\text { "entreajuda", "confiança", "união", "abertura". } \\
\text { Ex.: "E há muito isso de ir ter e dizer assim } \\
\text { "olha isto hoje não me correu bem, há aqui } \\
\text { qualquer coisa que me está a falhar». E pronto, } \\
\text { há sempre aquele espirito de entreajuda." (PD); } \\
\text { "(...) eu acho que o que é de valorizar aqui é o } \\
\text { relacionamento entre as pessoas porque se } \\
\text { aprende." (PE). }\end{array}$ \\
\hline & $\begin{array}{l}\text { Reuniões/Momentos informais } \\
\text { Ex.: "E como é que fazemos? Nem que seja } \\
\text { à hora do almoço, vamos almoçar, falamos, eu } \\
\text { digo, ou eu ou o colega diz «olha eu estou aqui } \\
\text { com um problema»" (PD). }\end{array}$ \\
\hline & $\begin{array}{l}\text { Estabilidade do corpo docente } \\
\text { Ex.: "Como o quadro neste momento está } \\
\text { mais ou menos estável, há sempre um colega ou } \\
\text { outro que entra mas aqui as pessoas } \\
\text { relacionam-se muito bem e há sempre um } \\
\text { espirito de interajuda muito grande" (PD). }\end{array}$ \\
\hline & $\begin{array}{l}\text { Tipologia (TEIP) e dimensão da escola } \\
\text { Ex.: "Este processo do TEIP também veio } \\
\text { obrigar, entre aspas, a que isto [colaboração] } \\
\text { aconteça. Porque como temos que articular } \\
\text { muito mais (...) mesmo a nível de conteúdos nós } \\
\text { partilhamos muito.” (PD). }\end{array}$ \\
\hline & $\begin{array}{l}\text { Disponibilidade/Motivação docente } \\
\text { Ex.: “(...) quando eles querem, também os } \\
\text { encontro até na saida da escola, no café, na hora } \\
\text { do almoço, eles conseguem falar na mesma de }\end{array}$ \\
\hline
\end{tabular}


escola, daquilo que eles pretendem, portanto,

é... tem evoluido bastante." (PB).

- Trabalhar em projeto(s)

Tabela 3.

Fatores inibidores da aprendizagem colaborativa docente

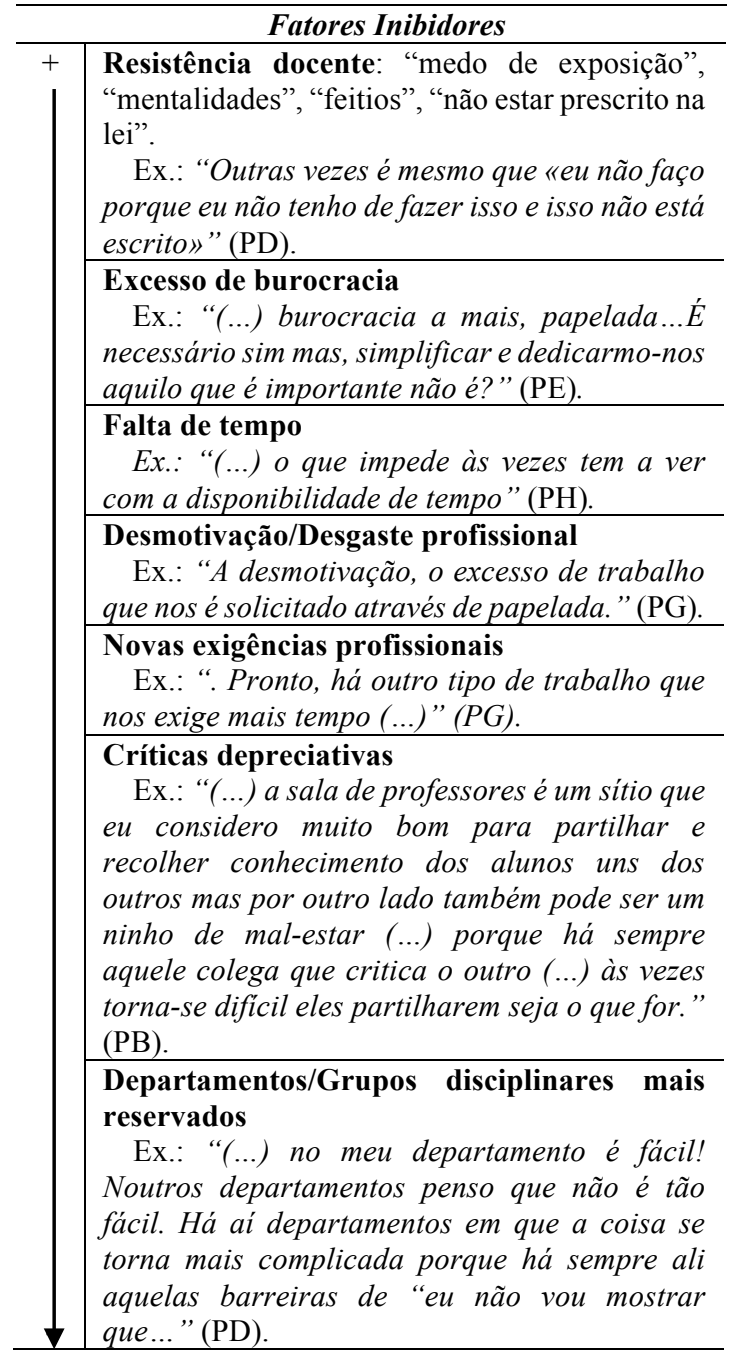

Salientamos que, após análise dos fatores que compõem os distintos campos, se percebe a existência de uma interligação entre a maioria deles, o que potencia ou não o desenvolvimento da aprendizagem colaborativa docente no local de trabalho. A título de exemplo, o facto do corpo docente ser estável, favorece o desenvolvimento de relações saudáveis, de qualidade e confiança, que por sua vez despoleta espontaneamente momentos informais de diálogo e partilha, abordando-se temas respeitantes à escola como a exposição de dúvidas, troca de materiais pedagógicos, partilha de métodos, de situações relativas a alunos etc.

"Como o quadro neste momento está mais ou menos estável (...) há sempre um espirito de interajuda muito grande" (PD);

“(...) eu sei que eles fazem reuniões formais $e$ informais para combinarem coisas na escola, sejam pedagógicas, sejam a nível de atividades portanto, eles conseguem articular muito bem uns com os outros" (PB);
“(...) não havendo esses momentos informais iria obrigar a que nós ficássemos mais tempo para nesses momentos formais se concluírem tarefas e os momentos informais servem para isso." (PH).

Por outro lado, o muitas vezes mencionado excesso de burocracia e as novas e frequentes exigências impostas a estes profissionais potenciam falta de tempo devido ao excesso de trabalho e funções e um consequente desgaste que desperta resistências e não favorece a predisposição para a partilha, para o diálogo e essencialmente para a colaboração.

“(...) perde-se tanto tempo com tanta coisa e reuniõezinhas (...) que os meus colegas estão um bocado desgastados, pouco motivados para muitas coisa" (PI);

"(...) as pessoas chegam às vezes a meio do periodo estão exaustas pelo volume do trabalho e pelas constantes alterações (...) os docentes estão constantemente a sofrer. " (PH).

De modo geral, os fatores facilitadores encontram-se mais relacionados com uma dimensão pessoal e relacional e, por sua vez, os fatores inibidores emanam, na sua maioria, de decisões advindas das políticas educativas. Apesar disso, e de acordo com o diretor do agrupamento, "a matriz que está mais evidente neste momento é no sentido da convergência e da articulação de esforços, da abertura entre as pessoas. " (PA).

\section{Conclusões}

Um ensino de qualidade pode representar um desafio significativo para os professores, na medida em que o mesmo requer reflexão e aprendizagem permanente e colaborativa, sendo este desafio transformador dos propósitos e dos resultados a favor do desenvolvimento do professor.

Neste sentido, para os professores, os momentos e espaços informais são valorizados e entendidos como momentos fulcrais para a aprendizagem colaborativa, com consequências no aperfeiçoamento do desempenho do professor na sala de aula. As relações interpessoais, baseadas na interajuda e na empatia, também assumem relevância nos contextos educativos que querem aprender de modo colaborativo.

Por seu turno, as experiências profissionais vivenciadas em práticas movidas por projetos pedagógicos, entre professores que compõem o corpo docente da escola há vários anos, colaboram para um trabalho docente mais rico e partilhado, com consequências na aprendizagem dos alunos.

Todavia, é de realçar as políticas educativas portuguesas emanadas nas últimas décadas que, na procura da qualidade no ensino, causaram mal estar nas escolas. Esta forma de estar/sentir a escola, provocada pelo excesso de novas tarefas e de trabalho burocrático, implicou falta tempo para refletir e aprender a ser melhor professor.

Em consequência deste modo de estar na profissão, os professores sentem-se desmotivados e cansados para aprender colaborativamente na escola, revelando 
desgaste profissional para continuar a lutar por uma profissão que escolheram por gosto. Tal facto merece atenção por parte dos políticos, dos investigadores e dos professores, pois pode conduzir a consequências particularmente nefastas, no desgaste e desencanto profissional (Herdeiro \& Silva, 2016) e consequente qualidade do ensino.

\section{Referências}

Apple, M. \& Jungck, S. (1992). You Don't Have to Be a Teacher to Teach This Unit: Teaching, Technology and Control in the Classroom. In A. Hargreaves \& M. Fullan (Ed.) Understanding Teacher Development. New York: Teachers College Press.

Bryman, A. (1988). Quantityandquality in social research. London: Routledge.

Costa, I. A. (2008). WebQuest na aula de matemática: Um estudo de caso com alunos do $10^{\circ}$ ano de escolaridade. Dissertação de Mestrado, Braga: Instituto de Educação e Psicologia, Universidade do Minho.

Darling-Hammond, L. (2010). Reconhecer e potenciar a eficacia docente: Guia para decisores políticos. In M. A. Flores (Org.) A avaliação de professores numa perspetiva internacional. Sentidos e implicações (pp. 197-235). Porto: Areal Editores.

Davesies, Ph. (1993). Eléments de psychodynamique du travail, Education Permanente, $\mathrm{n}^{\mathrm{o}} 116 / 3,33-46$.

Day, C. \& Sachs, J. (2004). Professionalism, performativity and empowerment: discourses in the politics and purposes of continuing professional development. In C. Day \& S. Sachs (Org.), International Handbook on the Continuing of Teachers. Maidenhead: Birks, Open University Press, 3-31

Herdeiro, R. \& Silva, A. M. C. (2016). Impact of New Public Management: Narratives of Portuguese Teachers. Asian Academic Research Journal of Social Sciences \& Humanities, Volume 3, Issue 9, 122-135

Ponte, J. P. (2004). Pesquisar para compreender e transformar a nossa prática. Educar em Revista, vol.2, $\mathrm{n}^{\mathrm{o}} 3,37-66$.

Ross, J. \& Bruce, C. (2007). Profissional Development Effects on Teacher Efficacy: Results of Randomized Field Trial. In The Journal of Educational Research, v. 101 (1), 50-60.

Snoek, N. (2007). O envolvimento das escolas e dos professores na aprendizagem dos professores: ao encontro de parcerias e de comunidades aprendentes. In Presidência Portuguesa do Conselho da União Europeia, Conferência Desenvolvimento Profissional de professores para a qualidade e para a equidade da aprendizagem ao longo da vida. Lisboa.

Stake, R. E. (1995). Theartof case study research. ThousandOaks: Sage Publications.

Tavares, J. (1996). Uma sociedade que aprende e se desenvolve. Relações Interpessoais. Porto: Porto Editora.

Yin, R. (1994). Case study research: designandmethods. ThousandOaks: Sage Publications. 